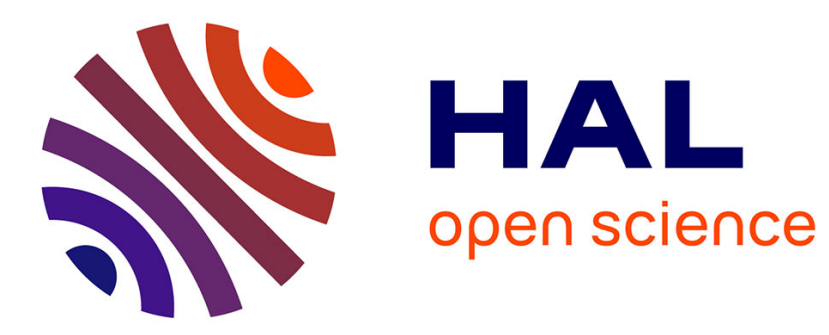

\title{
Analytical Approach for Air-gap Modeling of Field-Excited Flux-Switching machine: No-load Operation
}

Benjamin Gaussens

\section{- To cite this version:}

Benjamin Gaussens. Analytical Approach for Air-gap Modeling of Field-Excited Flux-Switching machine: No-load Operation. IEEE Transactions on Magnetics, 2012, pp.X. hal-00880919

\section{HAL Id: hal-00880919 https://hal.science/hal-00880919}

Submitted on 7 Nov 2013

HAL is a multi-disciplinary open access archive for the deposit and dissemination of scientific research documents, whether they are published or not. The documents may come from teaching and research institutions in France or abroad, or from public or private research centers.
L'archive ouverte pluridisciplinaire HAL, est destinée au dépôt et à la diffusion de documents scientifiques de niveau recherche, publiés ou non, émanant des établissements d'enseignement et de recherche français ou étrangers, des laboratoires publics ou privés. 


\title{
Analytical Approach for Air-gap Modeling of Field-Excited Flux-Switching machine: No-load Operation
}

\author{
Benjamin Gaussens ${ }^{12}$, Student Member, IEEE, Emmanuel Hoang ${ }^{1}$, Olivier de la Barrière ${ }^{1}$, \\ Jacques Saint-Michel ${ }^{2}$, Michel Lécrivain ${ }^{1}$, and Mohamed Gabsi ${ }^{1}$, Member, IEEE \\ 1 SATIE, ENS Cachan, CNRS, UniverSud, 61 av. du President Wilson, Cachan F-94230, France \\ ${ }^{2}$ Leroy Somer, Emerson, EPG Division, Sillac, Bd Marcellin Leroy - 16015 Angoulême Cedex, France
}

\begin{abstract}
This paper presents a general and accurate approach to determine the no-load flux of field-excited flux-switching (FE-FS) machines. These structures are inherently difficult to model due to their doubly-slotted air-gap. This analytical approach is based on MMF-permeance theory. The analytical model developed is extensively compared to field distribution obtained with 2D Finite Element (2D FE) Simulations. The good agreement observed between analytical model and 2D FE results emphasizes the interest of this general approach regarding the computation time. Hence, this analytical approach is suitable for optimization process in presizing loop. Furthermore, based on the field model, classical electromagnetic performances can be derived, such as flux-linkage and back-electromotive force (back-EMF) and also, unbalanced magnetic force. Once again, FE results validate the analytical prediction, allowing investigations on several stator-rotor combinations, or optimization of the back-EMF.
\end{abstract}

Index Terms-Analytical model, magnetic field, switched flux, flux-switching, slotting effect, air-gap permeance, modified magnetomotive force.

\section{INTRODUCTION}

$\mathbf{F}$ LUX-Switching (FS) machines have attracted considerable attention in recent years, especially topologies using permanent magnet (Permanent Magnet Flux-Switching PM-FS machines). To the author's knowledge, a single-phase fluxswitching alternator was firstly described in the 50's [1]. A single phase and a three phase flux-switching topologies were further studied in [2][3], where bipolar flux principle has been revealed. Since then, extensive work was proposed notably in United-Kingdom [4][5][6], in Japan [7] and in France [8][9][10]. Their large torque capability with practically sinusoidal back-electromotive force (EMF) makes them really interesting. Also, their robust structure, with a passive rotor and all active parts located in the stator allows brushless operation with reduced maintenance. For all these reasons, the PM-FS machine appears to be eligible for many industrial applications.

However, the difficult flux control capability in PM excited topologies is in contradiction with wide speed operation (constant power region), though, Hybrid-Excited Flux-Switching (HE-FS) machines were proposed combining the effect of permanent magnet with an additional DC-coil allowing good flux regulation. They have been analyzed extensively particularly in terms of their potential to extend the flux-weakening range of permanent magnet machines and to improve efficiency [11]. In the literature different HE-FS topologies are listed. Some of them can be classified as serie flux path HE-FS machine [12][13] and others as parallel flux path HE-FS machine [14].

Finally, Field-Excited Flux-Switching (FE-FS) machines

Manuscript received February 17, 2012; revised April 16, 2012; accepted April 18, 2012. Corresponding author: B. Gaussens (e-mail: gaussens@satie.ens-cachan.fr).

Color versions of one or more of the figures in this paper are available online at http://ieeexplore.ieee.org.

Digital Object Identifier ... were proposed. Few investigations were undertaken but everybody agree that this topology is particularly attractive for low cost-operation [15][16][17]. With a fully controllable flux, FEFS machines are similar to wound field synchronous machines except that they have inherent static excitation, i.e., without brushes. Fig. 1 shows an elementary cell of classical FE-FS machines. It can be seen that this topology has overlapping windings, which will result in a higher copper consumption. To overcome this problem, authors of [18][19] proposed an innovative topology, still based on flux-switching principle, but with modular rotor and non-overlapping windings. In this paper, the focus will be on classical FE-FS machine.

\section{A. Principle of Operation}

The flux-switching principle is briefly reminded in Fig. 1. Similar to the classical PM-FS machine, in the FE-FS machine, the negative and positive maximum flux-linkage of coil A1 occurs when a rotor pole is approximately aligned with one of the stator teeth (Figs. 1.(a) and (b)).

Therefore, a movement of the rotor induce a bipolar fluxlinkage and hence, an alternating back-EMF (Fig. 1.(c)). In the literature a significant number of publications are proposing analytical modeling of the slot effect on the air-gap magnetic field. An accurate model to account for the slot influence is of first interest here, since saliency in these machines is directly related to the operating principle. In the first part of this article, we propose an original and low time-consuming analytical approach for modeling the doubly-salient air-gap.

\section{B. Modeling of the Flux-Switching Machine in the Literature}

As specified beforehand, the wealth of literature on FS machines has hardly addressed the issue of FE-FS topologies. The majority of papers were dedicated to PM-FS structures. Usually, numerical techniques such as finite element methods 


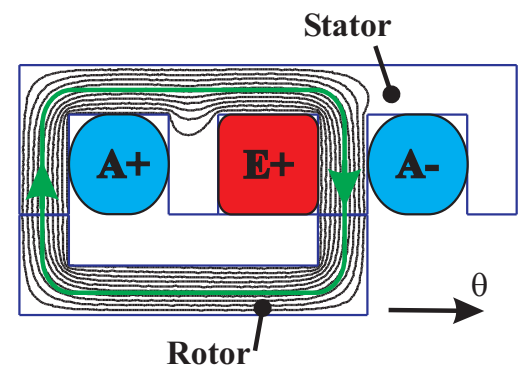

(a)

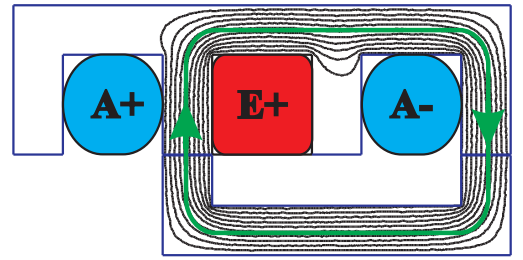

(b)

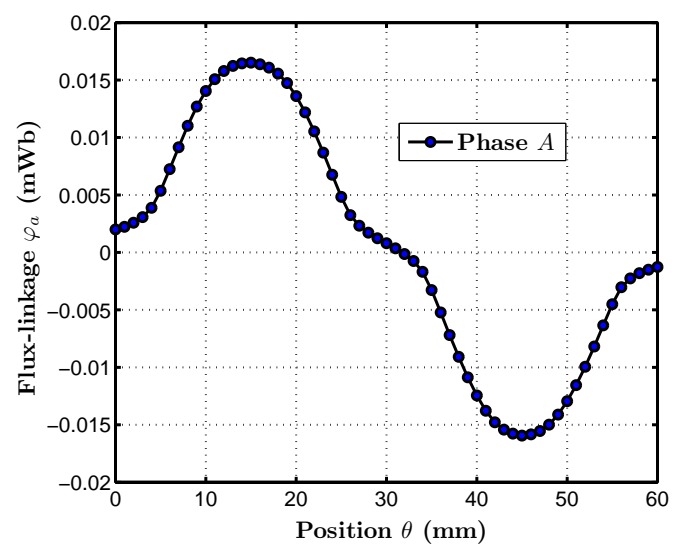

(c)

Fig. 1. Flux distribution in stator teeth with field excitation (Region E+) only: (a) Maximum flux-linkage position, (b) minimum flux-linkage position of coil A and (c) evolution of flux-linkage as function of rotor position $\theta$

are preferred to predict their electromagnetic performance, especially to take into account the non-linearity of magnetic materials [20][21]. Thanks to this approach, it is possible to predict fairly high saturation point observed in the air-gap or in the tooth core due to high field concentration effect. However, this approach is time-consuming particularly for initial sizing of an electrical machine. Hence, the development of an analytical model for initial performances calculations appears to be both challenging and meet a real design requirement. With the wider acceptance of genetic algorithms, optimization methods can be applied using the aforementioned analytical method. Some work of interest was proposed to model PM excited FS machine: Zhu et al. [22] have developed a non-linear Magnetic Equivalent Circuit (MEC) model, while authors of [23] solved the governing field-equations (Laplace and quasiPoisson equations) in the air-gap by means of Fourier analysis. The same authors have developed an interesting hybrid model [24] combining the advantages of the MEC model and Fourier analysis. As far as we know, analytical modeling of FE-FS machine has not yet been addressed.
In this paper, an analytical approach based on Magnetomotive-Force (MMF) and air-gap permeance distribution, for multi-phase FE-FS machine having any pole and slot number, will be presented. A doubly-salient air-gap permeance calculation is proposed. Only internal rotor topologies are considered for the sake of clarity. However, the model could be easily extended to external rotor configurations. The air-gap field distribution for different stator-rotor pole configurations, the phase flux-linkage, viz. the back-EMF and also unbalanced magnetic forces (UMF) are obtained using the model. Extensive FE simulations were performed to validate the approach.

\section{ANALYTICAL APPROACH FOR MODELING FIELD-EXCITED FLUX-SWITCHING MACHINE}

As was mentioned before, the analytical approach is based on MMF-permeance theory. Some assumptions are made in order to simplify the problem:

- Classically, the rotor and stator core have infinite permeability, hence, the magnetic saturation is not considered.

- Non-conductive materials (No eddy currents) and 2D problem (end effects are neglected).

The geometric representation of the doubly-slotted FE-FS machine is shown in Fig. 2. Stator and rotor slots opening are $\beta_{s} \theta_{s}$ and $\beta_{r} \theta_{r}$ respectively. The angular position in the air-gap is defined with $\nu$, and $\theta$ corresponds to the rotor position.

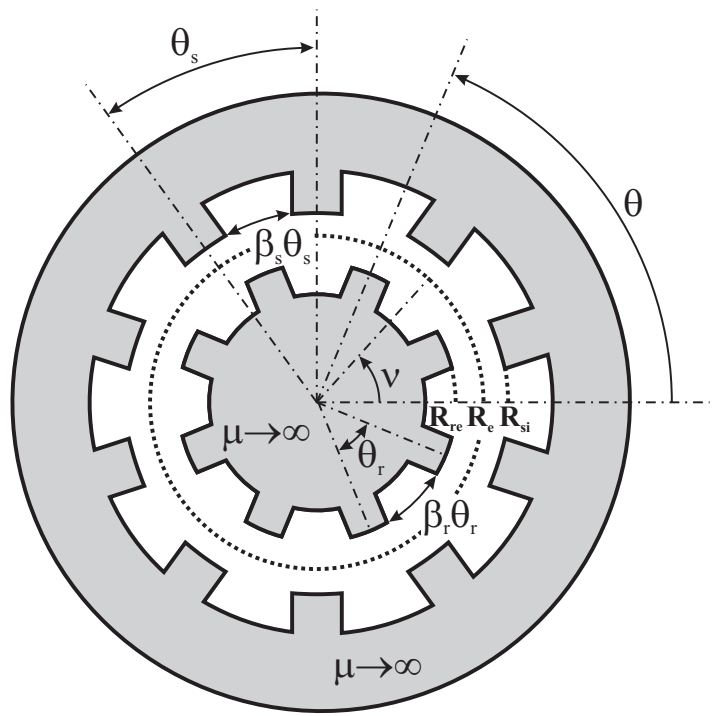

Fig. 2. Doubly-salient geometry of FE-FS machine with $N_{s}=10$ and $N_{r}=8$

\section{A. Flux density in the air-gap}

On the basis of Ampere's circuital law, and assuming that the MMF's drop in stator and rotor iron portions are neglected, the radial air-gap field distribution $B_{r}(\nu, \theta)$ can be expressed as

$$
B_{r}(\nu, \theta)=\mu_{0} M M F_{\text {exc }}(\nu, \theta) \Lambda(\nu, \theta)
$$


In accordance with (1), we require the doubly-slotted air-gap permeance $\Lambda(\nu, \theta)$ and the MMF created by current-carrying conductors distributed in the stator slots $M M F_{\text {exc }}(\nu, \theta)$. Fourier series expansions of both quantities are proposed in the next paragraphs.

\section{B. Magnetomotive Force created by DC-winding}

The MMF distribution created by excitation coils is shown in Fig. 3 and can be defined as a function by parts over $\left[0, \frac{8 \pi}{N_{s}}\right]$ :

$$
\begin{array}{ll}
M M F_{\text {exc }}(\nu)= & \\
\begin{cases}\frac{n_{s} I_{\text {exc }}}{\beta_{s} \theta_{s}} \nu & , \forall \nu \in\left[0, \frac{\beta_{s} \theta_{s}}{2}\right] \\
\frac{n_{s} I_{e x c}}{2} & , \forall \nu \in\left[\frac{\beta_{s} \theta_{s}}{2}, \theta_{s}\left(2-\frac{\beta_{s}}{2}\right)\right] \\
\frac{-n_{s} I_{e x c}}{\beta_{s} \theta_{s}}\left(\nu-2 \theta_{s}\right) & , \forall \nu \in\left[\theta_{s}\left(2-\frac{\beta_{s}}{2}\right), \theta_{s}\left(2+\frac{\beta_{s}}{2}\right)\right] \\
\frac{-n_{s} I_{e x c}}{2} & , \forall \nu \in\left[\theta_{s}\left(2+\frac{\beta_{s}}{2}\right), \theta_{s}\left(4-\frac{\beta_{s}}{2}\right)\right] \\
\frac{n_{s} I_{e x c}}{\beta_{s} \theta_{s}}\left(\nu-4 \theta_{s}\right) & , \forall \nu \in\left[\theta_{s}\left(4-\frac{\beta_{s}}{2}\right), 4 \theta_{s}\right]\end{cases}
\end{array}
$$

Every DC coil is wound around two stator teeth, so the stator tooth number $N_{s}$ must be even. In [15], different ways of connecting field conductors are proposed. However, since end-effects are neglected (2D problem), connections of DC coils do not impact electromagnetic performances. Expanding (2) into Fourier series over $\left[0, \frac{8 \pi}{N_{s}}\right]$ yields to

$$
M M F_{\text {exc }}(\nu) \sim \sum_{n=1,3,5 \ldots}^{+\infty} b_{n} \sin \left(n \frac{N_{s}}{4} \nu\right)
$$

where

$$
\begin{gathered}
b_{n}=\frac{2}{T} \int_{0}^{4 \theta_{s}} M M F_{e x c}(\nu) \sin \left(n \frac{N_{s}}{4} \nu\right) d \nu \\
=\frac{8 n_{s} I_{e x c}}{\beta_{s}(n \pi)^{2}} \sin \left(n \frac{\beta_{s} \pi}{4}\right)
\end{gathered}
$$

This formula is valid for any configuration (number of phase $q$ or stator tooth number $N_{s}$ ) considered.

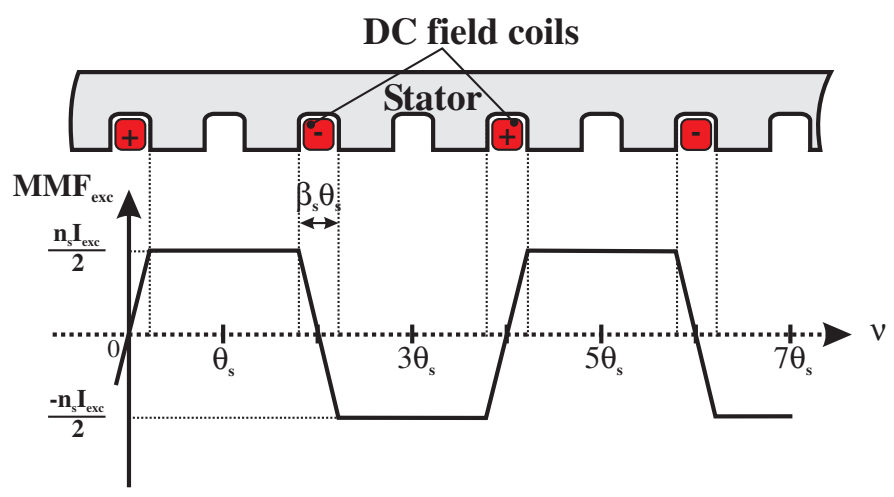

Fig. 3. The Magnetomotive Force created by the DC field coils $M M F_{\text {exc }}\left(\nu, n_{s} I_{\text {exc }}, \beta_{s}, \theta_{s}\right)$

\section{Doubly-slotted air-gap permeance function}

The slotting effect, which refers to a variation of reluctance around the periphery of the air-gap, has long been investigated in many papers. Two analytical approaches are mainly considered in the literature.

Some models consider relative permeance functions to modulate the radial flux calculated for a slotless motor. Conformal transformation can be employed to evaluate this relative permeance function [25]. One century ago, F.W. Carter used conformal mapping to derive the well-known Carter's coefficient [26]. Also, in 1993, a series of papers dealing with analytical modeling of brushless DC PM motors accounted for the slotting effect using a conformal transformation method [27]. It is worth mentioning that in the work [28][29] a complex relative permeance function was developed. By fully exploring conformal transformation properties, authors can also determine the tangential field in the air-gap. The relative air-gap permeance can also be predicted considering idealized flux lines under the slot [30][31][32]. The second approach consists of solving the Laplace/quasi-Poissonian equation in different sub-domains [33][34] [35][36].

In this work, the first approach is considered, and a permeance function based on the mean flux path under the slot opening is proposed.

In Fig. 4, the extended magnetic circuit of FE-FS machine is presented. The doubly-slotted air-gap is divided into two regions at its mean radius: Stator slots opposite to a smooth surface (Region I) and rotor slots also opposite to the same smooth surface (Region II). From Fig. 4, we can express the reciprocal of the air-gap permeance $g(\nu, \theta)$ as

$$
g(\nu, \theta)=e+\delta_{s}(\nu)+\delta_{r}(\nu, \theta)
$$

where, $\delta_{s}(\nu)$ and $\delta_{r}(\nu, \theta)$ are respectively the stator and rotor, additional air-gap introduced by slotting. Notably, the rotation of the rotor is directly accounted for in the term $\delta_{r}(\nu, \theta)$. Finally, the permeance function $\Lambda(\nu, \theta)$ is derived simply from (5) as

$$
\Lambda(\nu, \theta)=\frac{1}{g(\nu, \theta)}
$$

In Fig. 5, idealized magnetic flux-lines under an infinitely deep slot are depicted. Assuming quarter-circular flux-lines (with radii $R_{1}$ and $R_{2}$ ), it yields the arc lengths $\Gamma_{1}$ and $\Gamma_{2}$

$$
\left\{\begin{array}{l}
\Gamma_{1}=\pi R_{s i} \sin \left(\frac{\nu}{2}\right) \\
\Gamma_{2}=\pi R_{s i} \sin \left(\frac{\beta_{s} \theta_{s}}{2}-\frac{\nu}{2}\right)
\end{array}\right.
$$

Finally, the additional air-gap $\delta_{s}(\nu)$ corresponds to an equivalent length $\left(\Gamma_{1}\right.$ and $\Gamma_{2}$ in parallel) that can be expressed as follows

$\delta_{s}(\nu)= \begin{cases}\frac{\pi R_{s i}}{2} \frac{\sin \left(\frac{\nu}{2}\right) \sin \left(\frac{\beta_{s} \theta_{s}}{2}-\frac{\nu}{2}\right)}{\sin \left(\frac{\beta_{s} \theta_{s}}{4}\right) \cos \left(\frac{\nu}{2}-\frac{\beta_{s} \theta_{s}}{4}\right)} & , \forall \nu \in\left[0, \beta_{s} \theta_{s}\right] \\ 0 & , \forall \nu \in\left[\beta_{s} \theta_{s}, \theta_{s}\right]\end{cases}$ 


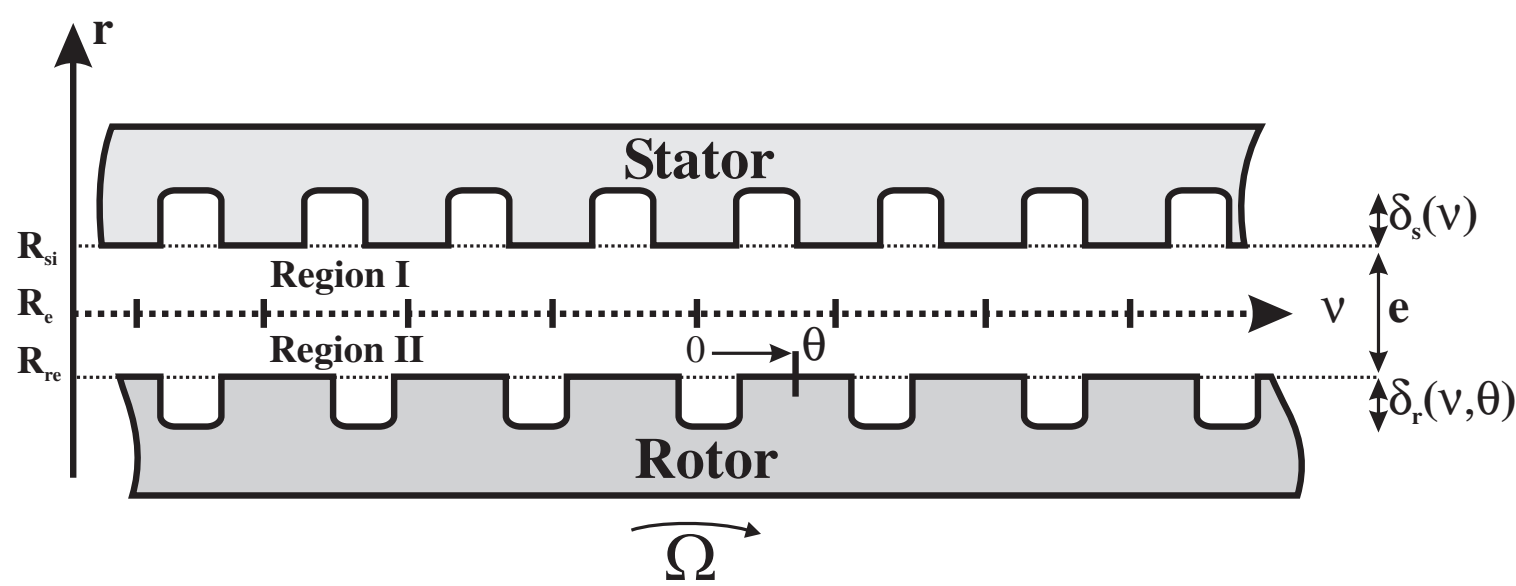

Fig. 4. The extended magnetic circuit of the FE-FS machine in pseudopolar coordinate to evaluate the air-gap permeance $\Lambda(\nu, \theta)$

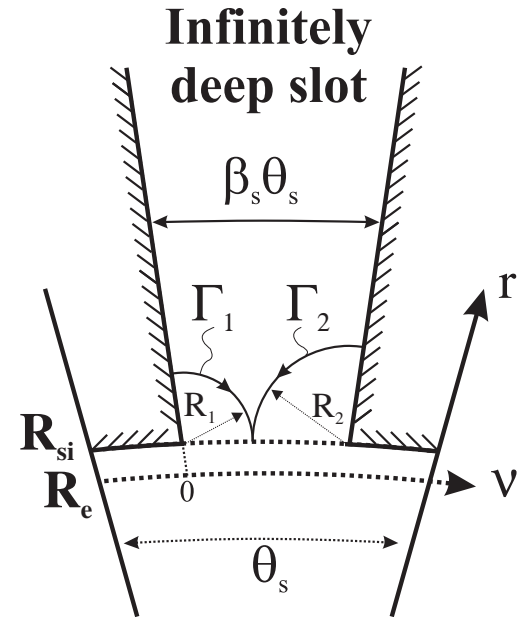

Fig. 5. Magnetic flux-path under an infinitely deep slot

with $R_{s i}$ the internal radius of stator.

After linearization, and by using Fourier series expansion of (8), it gives for the stator

$$
\delta_{s}(\nu) \sim a_{0}^{(I)}+\sum_{n=1}^{+\infty} a_{n}^{(I)} \cos \left(n N_{s} \nu\right)+b_{n}^{(I)} \sin \left(n N_{s} \nu\right)
$$

where $a_{0}^{(I)}, a_{n}^{(I)}$ and $b_{n}^{(I)}$ are

$$
\begin{gathered}
a_{0}^{(I)}=\frac{1}{T} \int_{0}^{\theta_{s}} \delta_{s}(\nu) d \nu \\
=\frac{R_{s i}\left(\pi \beta_{s}\right)^{2}}{6 N_{s}} \\
a_{n}^{(I)}=\frac{2}{T} \int_{0}^{\theta_{s}} \delta_{s}(\nu) \cos \left(n N_{s} \nu\right) d \nu \\
=-\frac{R_{s i}}{2 N_{s} n^{2}}\left\{\left(1+\cos \left(2 \pi n \beta_{s}\right)\right)-\frac{1}{\pi n \beta_{s}} \sin \left(2 \pi n \beta_{s}\right)\right\}
\end{gathered}
$$

$$
\begin{gathered}
b_{n}^{(I)}=\frac{2}{T} \int_{0}^{\theta_{s}} \delta_{s}(\nu) \sin \left(n N_{s} \nu\right) d \nu \\
=\frac{R_{s i}}{2 N_{s} n^{2}}\left\{\frac{1}{\pi n \beta_{s}}\left(1-\cos \left(2 \pi n \beta_{s}\right)\right)-\sin \left(2 \pi n \beta_{s}\right)\right\}
\end{gathered}
$$

Fig. 6 presents the evolution of the additional air-gap under the stator slot considering respectively Eq. (8) and Eq. (9). Excellent agreement is observed between both expressions as long as $N_{s}>3$. However, configurations with less than 3 slots are unlikely.

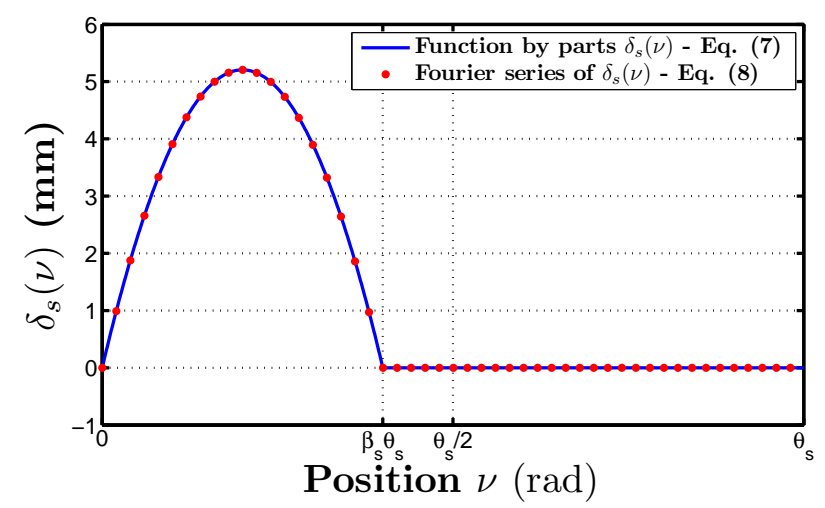

Fig. 6. Comparison between the additional air-gap function $\delta_{s}(\nu)$ (Eq. (8)) and its Fourier series development (Eq. (9))

The same procedure is applied to the rotor slots (Region II) and, including the influence of rotation, the term $\delta_{r}(\nu, \theta)$ is given by

$$
\begin{aligned}
\delta_{r}(\nu, \theta) \sim a_{0}^{(I I)}+\sum_{n=1}^{+\infty} a_{n}^{(I I)} & \cos \left(n N_{r}(\nu-\theta)\right) \\
& +b_{n}^{(I I)} \sin \left(n N_{r}(\nu-\theta)\right)
\end{aligned}
$$

where the mean value $a_{0}^{(I I)}$ is

$$
a_{0}^{(I I)}=\frac{R_{r e}\left(\pi \beta_{r}\right)^{2}}{6 N_{r}}
$$


with $R_{r e}$ the internal rotor radius. Like (11) and (12), the Fourier coefficients are found to be

$a_{n}^{(I I)}=-\frac{R_{r e}}{2 N_{r} n^{2}}\left\{\left(1+\cos \left(2 \pi n \beta_{r}\right)\right)-\frac{1}{\pi n \beta_{r}} \sin \left(2 \pi n \beta_{r}\right)\right\}$

and

$b_{n}^{(I I)}=\frac{R_{r e}}{2 N_{r} n^{2}}\left\{\frac{1}{\pi n \beta_{r}}\left(1-\cos \left(2 \pi n \beta_{r}\right)\right)-\sin \left(2 \pi n \beta_{r}\right)\right\}$

(16)

Fig. 7.(a) represents the equivalent air-gap for a 10-6 slots configuration. The spectra of $\Lambda(\nu, \theta)$ (Fig. 7.(b)) shows that the space harmonics introduced by stator and rotor teeth are well accounted for. Classically, $\left|i N_{s}\right|$ and $\left|i N_{r}\right|$ harmonics are introduced by each of the stator and rotor wave permeances, where $i$ is an integer. Also, their interactions are found to be $i\left|N_{s}-N_{r}\right|$ and $i N_{s} \pm\left|N_{s}-N_{r}\right|$ harmonics.

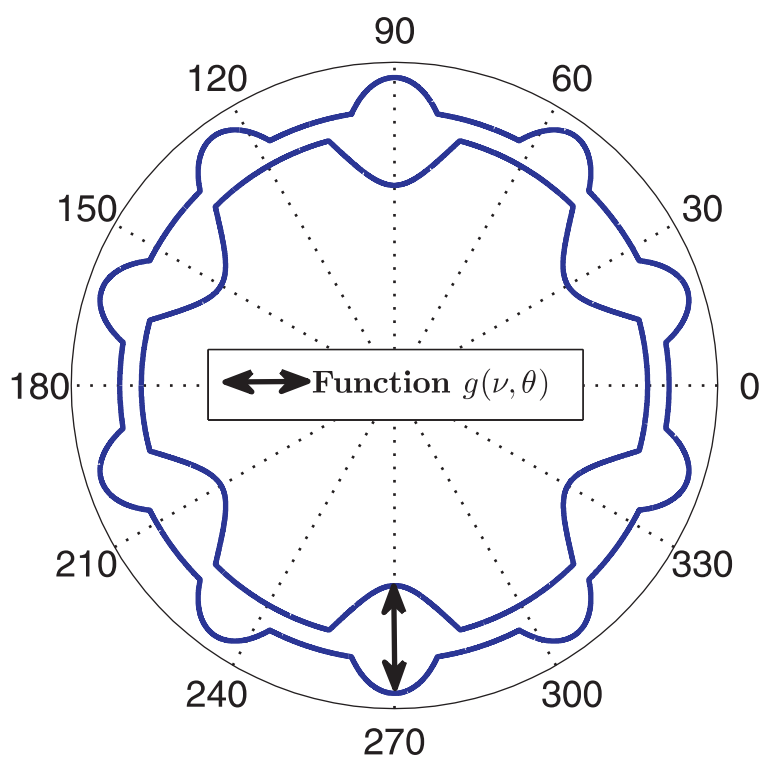

(a)

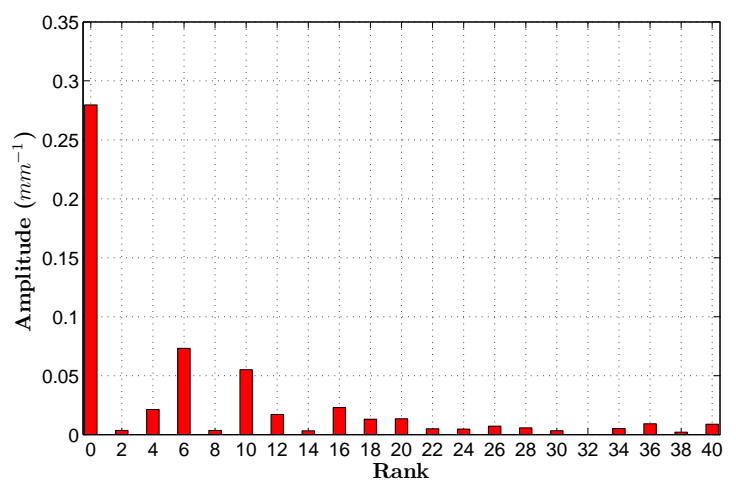

(b)

Fig. 7. (a) Evolution of function $g\left(\nu, \theta=0\right.$ ) (with $N_{s}=10, N_{r}=6$, $\beta_{s}=\beta_{r}=0.5, R_{s i}=50 \mathrm{~mm}$ and $e=2 \mathrm{~mm}$ ) and (b) spectra of the air-gap permeance $\Lambda(\nu, \theta)$

\section{Modified Magnetomotive Force}

In this part, we introduce the need of a compensation of the MMF created by excitation coils. Indeed, depending on the stator-rotor configuration, some permeance harmonics and field coil MMF harmonics will present the same wave length, so as an offset is introduced. Since, Maxwell's equations (with Gauss's law for magnetism) imply $\operatorname{div} \vec{B}=0$, we introduce the coefficient $\kappa_{c}$

$$
\kappa_{c}(\nu, \theta)=-\frac{\int_{0}^{2 \pi} M M F_{e x c}(\nu) \Lambda(\nu, \theta) d \nu}{\int_{0}^{2 \pi} \Lambda(\nu, \theta) d \nu}
$$

and (3) is modified as follows

$$
M M F_{e x c}(\nu, \theta) \sim \kappa_{c}(\nu, \theta)+\sum_{n=1,3,5 \ldots}^{+\infty} b_{n} \sin \left(n \frac{N_{s}}{4} \nu\right)
$$

In fact, $\kappa_{c}$ refers to the rotor scalar magnetic potential, that was assumed zero in Section II.B. After obtaining the airgap permeance and the DC coil MMF, the radial air-gap flux density can be predicted according to (1), (6) and (18).

\section{NO-LOAD FLUX AND BACK-EMF PREDICTION AND COMPARISON WITH FINITE ELEMENT SIMULATIONS}

In this part, the previously developed analytical model is extensively compared to 2D FE simulations for different kind of stator-rotor topologies. Common parameters of the different considered structures are detailed in Table I. In order to use the same assumption as for the analytical model, highly permeable linear material $\left(\mu_{r}=1000\right)$ is considered in the simulations (the free-of-charge FEMM software was used).

TABLE I

COMMUN PARAMETERS OF THE MODEL

\begin{tabular}{ccc}
\hline \hline Description & Symbol & Numerical value \\
\hline \hline Inner radius of stator & $R_{s i}$ & $126.6 \mathrm{~mm}$ \\
\hline Middle air-gap radius & $R_{e}$ & $126.35 \mathrm{~mm}$ \\
\hline Outer radius of rotor & $R_{r e}$ & $126.1 \mathrm{~mm}$ \\
\hline Active axial length & $L_{a}$ & $45 \mathrm{~mm}$ \\
\hline DC field MMF & $n_{s} I_{e x c}$ & $1200 \mathrm{~A} . t u r n$ \\
\hline Speed & $\Omega$ & $1300 \mathrm{rpm}$ \\
\hline
\end{tabular}

\section{A. Air-gap field distribution}

\section{1) Single-phase structures}

We firstly consider and investigate single phase configurations. Stator and rotor combinations are easily defined as

$$
N_{s}=2 N_{r}
$$

The radial flux density distributions in the middle of the airgap $\left(r=R_{e}\right)$ for a 12-6 slots configuration and different rotor positions are plotted in Fig. 8.

Contrary to classical wound field excited synchronous machines, the air-gap field distribution exhibits significant harmonics due to inherent doubly-saliency. Even so, from Fig. 8 , we can observe an excellent agreement between analytical 


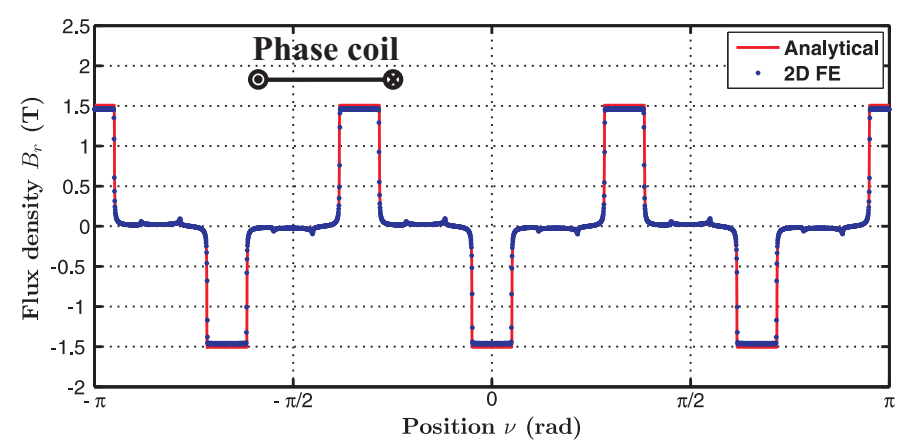

(a)

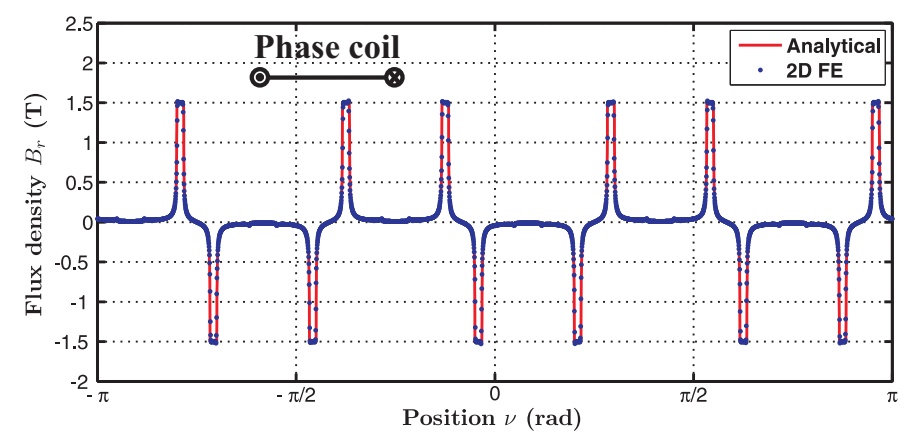

(c)

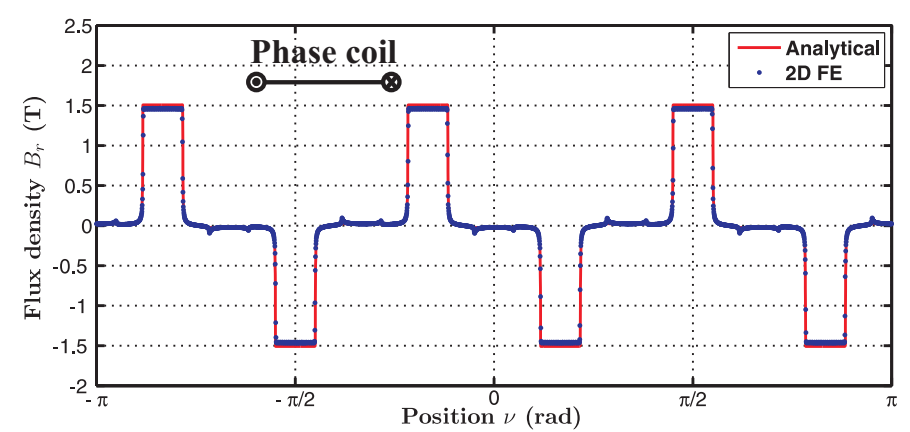

(e)

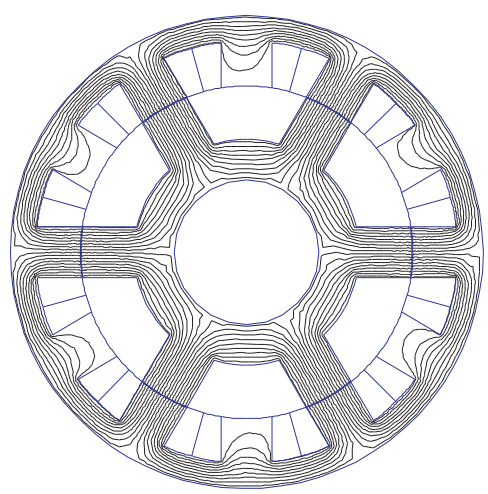

(b)

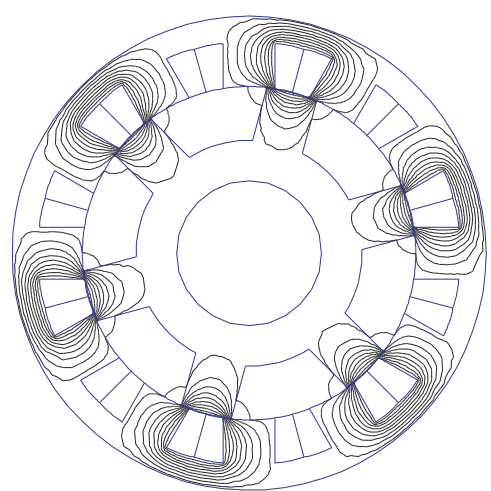

(d)

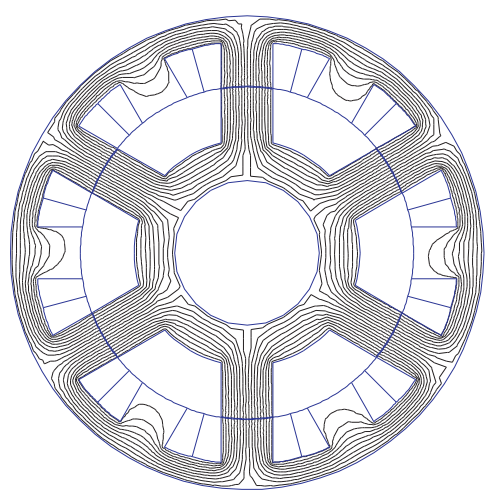

(f)

Fig. 8. Magnetic flux density in middle of air-gap $\left.B_{r}(\nu, \theta)\right|_{r=R_{e}}$ for a 12-6 slots configuration (single phase) (with $\beta_{s}=0.6$, $L_{d s}=L_{d r}$ and $n_{s} I_{\text {exc }}=1200$ A.turn) and for different rotor positions: (a) $B_{r}$ distribution at initial position $\theta=0$ (d-axis) and (b) the magnetic flux lines with FE software, (c) $B_{r}$ distribution at $\theta=\frac{\pi}{N_{r}}$ (q-axis) and (d) the magnetic flux lines, (e) $B_{r}$ distribution at $\theta=\frac{2 \pi}{N_{r}}$ (Minimum flux-linkage in the phase) and (f) the magnetic flux lines

and FE results. The relative error for the peak flux density does not exceed $3 \%$. Furthermore, the flux-switching principle can be observed by carefully examining Figs. 8.(a) and (c), i.e., for maximum and minimum flux-linkage in the phase. Indeed, the air-gap flux density is locally inverted (or switched) over the coil phase leading to a bipolar flux-linkage. Even for configurations which are difficult to model, such as in that shown in Fig. 9, where the stator slot opening is wider than the rotor tooth width, the analytical model gives quite a good evaluation of the air-gap field.

While for single phase structures, the no-load field distribution in the air-gap is well accounted for with $\frac{4 \pi}{N_{r}}$ periodicity. We explore in the next section $q$-phase structures.

\section{2) Multi-phase structures}

Air-gap field distribution for multi-phase structures is more complicated to assess, with symmetry often over $180^{\circ}$ or $360^{\circ}$ (for non-symmetrical configurations). Indeed, unlike singlephase structures, we cannot define clearly a stator-rotor combination $\left(N_{s}-N_{r}\right)$. For one stator configuration, many rotor combinations are likely to work. While the model is devoted to multi-phase topologies, a special emphasis will be placed on 3 phase $(q=3)$ structures. In the interest of clarity and simplification, radial air-gap field distributions at $r=R_{e}$ for a 24 stator slots configuration ( 3 phases) and different rotor teeth are proposed in Appendix A (Figs. 19, 20, 21 and 22). It can be seen that with an even number of rotor teeth, $\mathrm{Br}$ distribution 


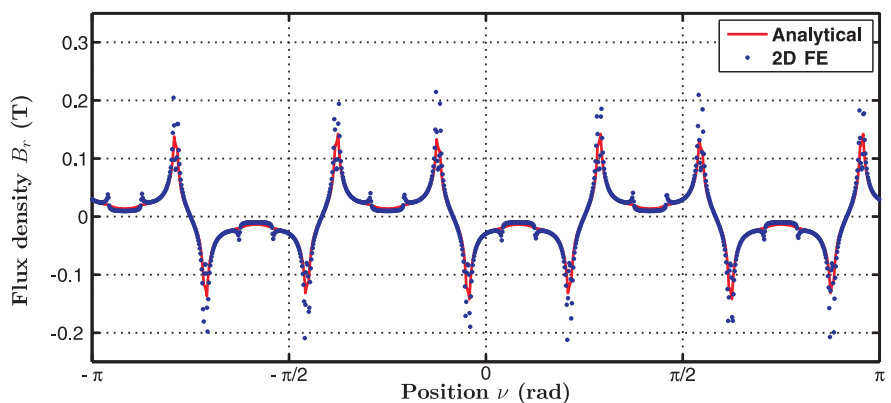

(a)

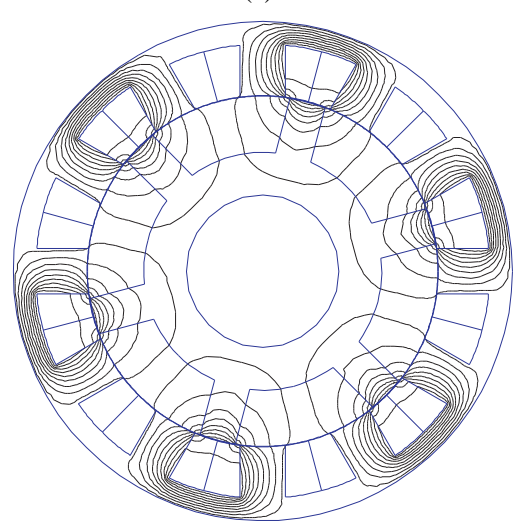

(b)

Fig. 9. Magnetic flux density in middle of air-gap $\left.B_{r}(\nu, \theta)\right|_{r=R_{e}}$ for a 126 slots configuration (single phase) (with $\beta_{s}=0.5, \beta_{r}=0.2$ and $n_{s} I_{\text {exc }}=$ 1200 A.turn) in q-axis position and with stator slot wider than rotor tooth: (a) $B_{r}$ distribution and (b) the magnetic flux lines with FE software

is $\pi$-periodic, whereas for odd one, $\mathrm{Br}$ is $2 \pi$-periodic. To sort different possible combinations, coefficients $\gamma=\operatorname{gcd}\left(N_{s}, N_{r}\right)$ and $n_{c}$ are introduced. For instance, periodicity of $B_{r}(\nu, \theta)$ for 3 phase structures, set out in Appendix A, is $2 \pi / \gamma$. The parameter $n_{c}$ refers to the number of individual coils (having different flux-linkage) per phase. That coefficient directly depends on winding configuration and so, it is acknowledged afterwards.

\section{B. Flux-linkage and back-EMF}

Since local quantities, i.e. air-gap field distributions, are fairly well predicted thanks to the analytical model, it is interesting to evaluate global quantities such as flux linkage and back-EMF. Furthermore, those global quantities can be used to evaluate, at no-load, electromagnetic performance and perform initial sizing of a structure. In the next section, the evaluation of flux linkage and back-EMF are discussed and analytical expressions are deduced. Particularly, stator and rotor configurations and also phase winding configurations (single or double-layers) are investigated and systematically compared to FE simulations.

The key differences between single and double layers FEFS machines are shown in Fig. 10. Indeed, in double layer machines, each phase stator slot contains two different phase coils while single layer machines (also designed as alternate pole wound machine in [37][38] for PM-FS machine) contain coils from only one phase. Hence, the flux-linkage calculation depends on the phase winding under consideration. The

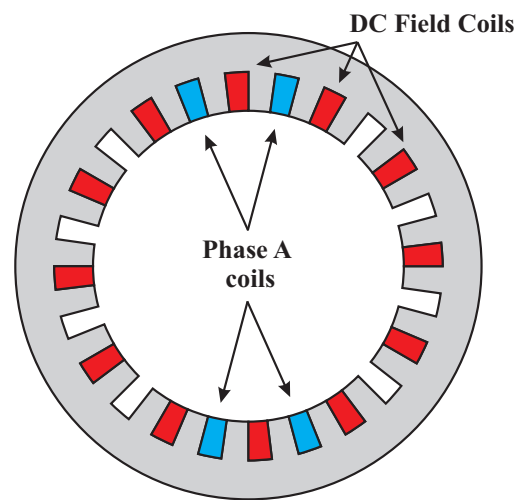

(a)

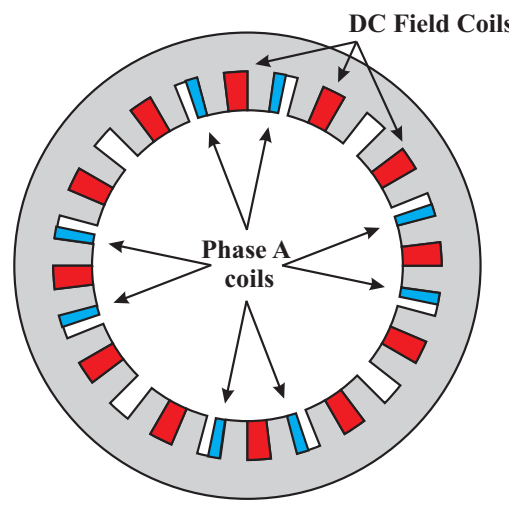

(b)

Fig. 10. Cross section of the FS machine of different phase winding configuration: (a) single-layer and (b) double-layer

classical technique to evaluate the flux-linkage of one coil is based on the integration of radial flux density over the coil.

However, as mentioned in [39], this technique does not take into account in an explicit manner the influence of slotting. For consistency in our demonstration, analytical results obtained by the integration of the flux density are compared to those obtained by 2D FE simulations with a direct integration of magnetic vector potential in slots. In so doing, we could completely validate the approach. The total phase flux-linkage is obtained by adding fluxes flowing through every coil belonging to the same phase. For single phase structures, it is reasonable to consider that each phase coil see the same the flux-linkage $\varphi_{s}$. So, the phase flux-linkage can be expressed directly as follows

$$
\varphi_{s}(\theta)=R_{e} L_{a} \int_{\frac{\theta_{s}}{2}}^{\frac{5 \theta_{s}}{2}} B_{r}(\nu, \theta) d \nu
$$

for single-layer configurations, or as follows

$$
\varphi_{s}(\theta)=R_{e} L_{a} \int_{\frac{\theta_{s}\left(1+\frac{\beta_{s}}{2}\right)}{2}}^{\frac{\theta_{s}\left(5-\frac{\beta_{s}}{2}\right)}{2}} B_{r}(\nu, \theta) d \nu
$$

for double-layer winding configuration. 
In multi-phase structures, as we shall see in subsequent sections, flux-linkages of different coils of the same phase differ. This phenomenon, firstly reported in [22], is inherent to FS machines, since relative positions between stator and rotor tooth over each coil are different. Hereafter, expressions of global flux-linkage depending on winding configuration and number of rotor teeth $N_{r}$ are derived. For the sake of clarity, only configurations with $N_{r}=N_{s} / 2 \pm \gamma$ have been investigated. Nevertheless, those configurations are the most promising in terms of power capability.

Finally, once the total flux-linkage is obtained, the backEMF $E_{s}$ is determined from

$$
E_{s}=-N_{t s p} \Omega \frac{\pi}{30} \frac{d \varphi_{s}}{d \theta}
$$

with $N_{t s p}$ the number of turns in series per phase.

Analytical evaluation of flux-linkage and back-EMF are, hereafter, compared to 2D FE simulations.

\section{1) Single-layer configuration}

The overall flux-linkage for single-layer winding configurations having $\gamma \geq 2$ and $n_{c}=N_{s} / 4 q \gamma$ coils can be derived as (20). Indeed, like single phase structures, the relative position between each phase coil and the rotor tooth is the same.

With regard to configurations with $\gamma=1$ and $n_{c}=N_{s} / 4 q$ coils, the total flux-linkage is found to be, for $n_{c}=2$,

$$
\varphi_{s}(\theta)=\frac{R_{e} L_{a}}{n_{c}}\left\{\sum_{i=0}^{n_{c}-1}(-1)^{i} \int_{\frac{\theta_{s}(1+8 q i)}{2}}^{\frac{\theta_{s}(5+8 q i)}{2}} B_{r}(\nu, \theta) d \nu\right\}
$$

In Fig. 11, the flux-linkage $\varphi_{s}$ for two rotor configurations $\left(N_{r}=10\right.$ et 13) and a single-layer winding configuration are plotted. Good agreements are observed for both configurations (with a relative error between $3-4 \%$ on the peak flux-linkage for the configuration $N_{r}=10$ or $N_{r}=13$ ). As mentioned before, for an odd number of rotor teeth $N_{r}(\gamma=1)$, the flux-linkage must be computed for two adjacent coils $\left(A_{1}\right.$ and $A_{2}$ ) (Fig. 11.(b)), while when $N_{r}$ is even $(\gamma=2)$, only the flux-linkage of one coil is needed (Fig. 11.(a)).

The back-EMF for the same configuration are presented in Figs. 12 and 13. The computation is done for a rotation speed $\Omega=1300 \mathrm{rpm}$. Both analytical and FE results are in close agreement. Moreover, back-EMF spectra (Figs. 12.(b) and 13.(b)) show that it is possible to correctly predict their harmonic content. Thus, the analytical model could be used to determine optimum stator and rotor relative slot openings (respectively $\beta_{s}$ and $\beta_{r}$ ).

\section{2) Double-layer configuration}

For double-layer winding configurations having $\gamma \geq 2$ and $n_{c}=N_{s} / 2 q \gamma$ coils, the phase flux-linkage $\varphi_{s}$ can be expressed as

$$
\varphi_{s}(\theta)=\frac{R_{e} L_{a}}{n_{c}}\left\{\sum_{i=0}^{n_{c}-1} \int_{\frac{\theta_{s}\left(1+4 q i-\frac{\beta_{s}}{2}\right)}{2}}^{\frac{\theta_{s}\left(5+4 q i-\frac{\beta_{s}}{2}\right)}{2}} B_{r}(\nu, \theta) d \nu\right\}
$$

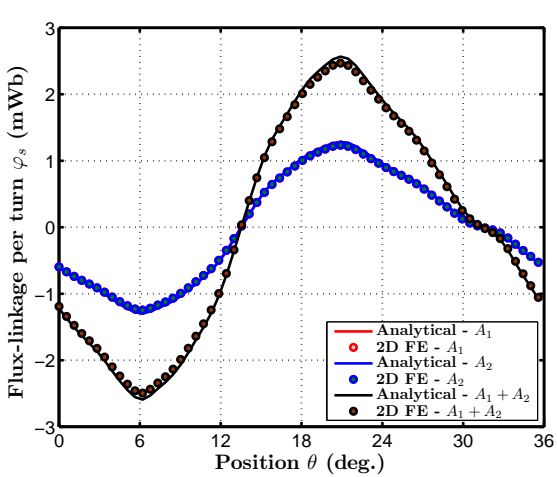

(a)

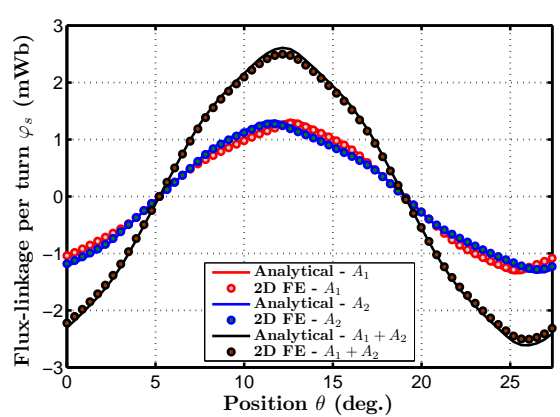

(b)

Fig. 11. Flux-linkage (per turn) waveform for a 24 stator slots structure and single-layer winding configuration (with $\beta_{s}=0.6, L_{d s}=L_{d r}$ and $n_{s} I_{\text {exc }}=1200$ A.turn): (a) 10 rotor teeth and (b) 13 rotor teeth

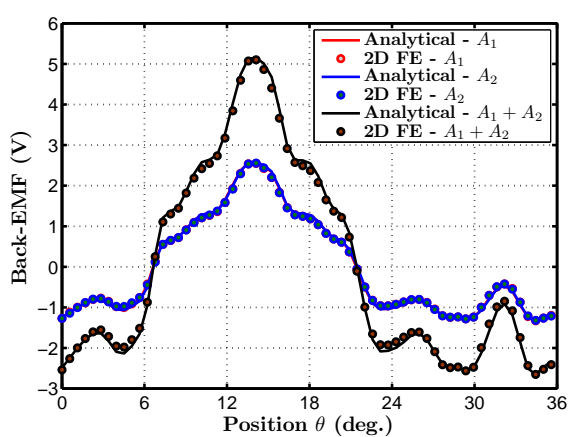

(a)

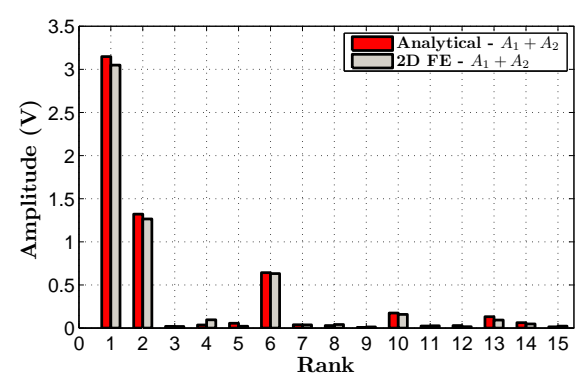

(b)

Fig. 12. Back-EMF waveform (a) and its spectra (b) for a 24-10 slots structure and single-layer winding configuration (with $\beta_{s}=0.6, L_{d s}=L_{d r}$, $n_{s} I_{\text {exc }}=1200$ A.turn and $\Omega=1300$ rpm) 


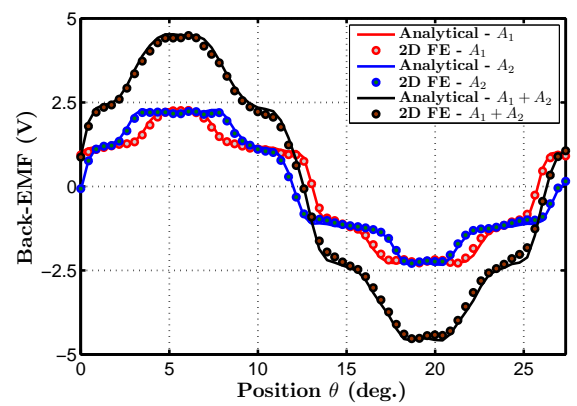

(a)

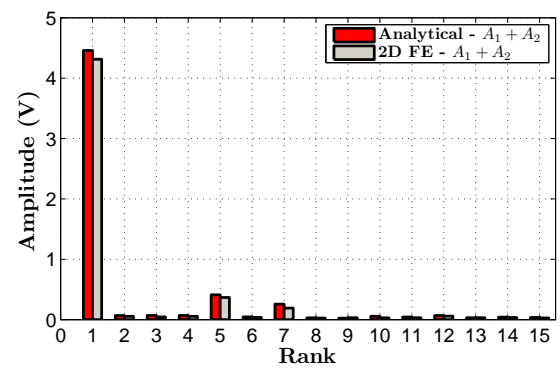

(b)

Fig. 13. Back-EMF waveform (a) and its spectra (b) for a 24-13 slots structure and single-layer winding configuration (with $\beta_{s}=0.6, L_{d s}=L_{d r}$, $n_{s} I_{\text {exc }}=1200$ A.turn and $\Omega=1300 \mathrm{rpm}$ )

According to (24), those configurations would have just 2 coils per phase having a slight difference on the flux-linkage.

Regarding configurations with $\gamma=1$ and $n_{c}=N_{s} / 2 q$ coils, it is possible to express the phase flux-linkage as (24) for $n_{c}=2$, and as follows,

$$
\begin{aligned}
& \varphi_{s}(\theta)=\frac{R_{e} L_{a}}{n_{c}} \\
& \left\{\sum_{i=0}^{\frac{n_{c}}{2}-1}(-1)^{i} \int_{\frac{\theta_{s}\left(1+4 q i-\frac{\beta_{s}}{2}\right)}{2}}^{\frac{\theta_{s}\left(5+4 q i-\frac{\beta_{s}}{2}\right)}{2}} B_{r}(\nu, \theta) d \nu\right. \\
& \left.-\sum_{i=\frac{n_{c}}{2}}^{n_{c}-1}(-1)^{i} \int_{\frac{\theta_{s}\left(1+4 q i-\frac{\beta_{s}}{2}\right)}{2}}^{\frac{\theta_{s}\left(5+4 q i-\frac{\beta_{s}}{2}\right)}{2}} B_{r}(\nu, \theta) d \nu\right\}
\end{aligned}
$$

for $n_{c}=4$.

Here, to compute the total flux-linkage, an integration over at least 4 coils per phase needs to be performed. Fluxlinkages for $N_{r}=11$ and $N_{r}=14$, in Fig. 14, demonstrate once again a good agreement between analytical and FE results. Also, it can be seen that each coil's flux-linkage is again slightly different, and the analytical model correctly predicts this phenomenon. The back-EMF and their spectra (at $\Omega=1300 \mathrm{rpm}$ ) are also in close agreement (See Figs. 15 and 16).

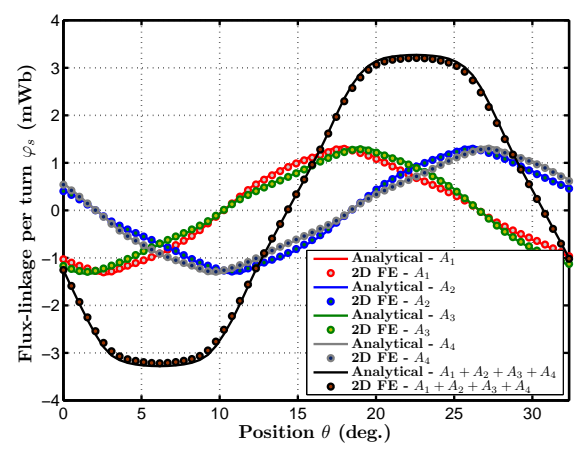

(a)

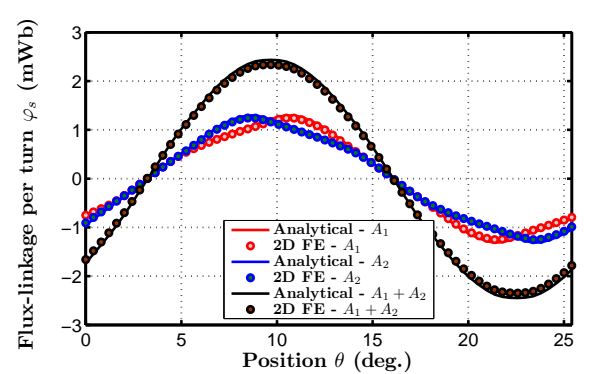

(b)

Fig. 14. Flux-linkage (per turn) waveform for a 24 stator slots structure and double-layer winding configuration (with $\beta_{s}=0.6, L_{d s}=L_{d r}$ and $n_{s} I_{\text {exc }}=1200$ A.turn): (a) 11 rotor teeth and (b) 14 rotor teeth

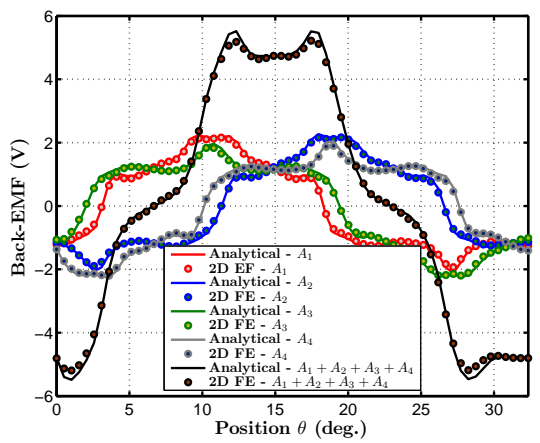

(a)

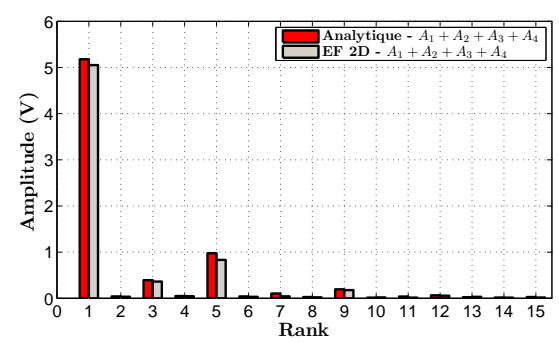

(b)

Fig. 15. Back-EMF waveform (a) and its spectra (b) for a 24-11 slots structure and double-layer winding configuration (with $\beta_{s}=0.6, L_{d s}=$ $L_{d r}, n_{s} I_{\text {exc }}=1200$ A.turn and $\Omega=1300 \mathrm{rpm}$ )

\section{Unbalanced Magnetic Forces Calculation}

A. Analytical expression of radial magnetic forces

Unbalanced magnetic force (UMF) is the overall magnetic force that acts on the rotor due to an asymmetric air-gap 


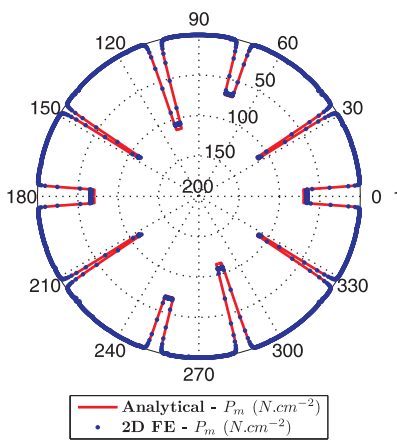

(a)

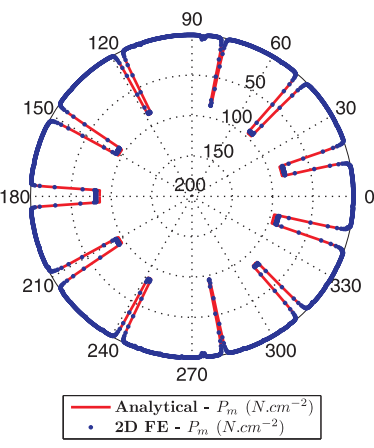

(b)

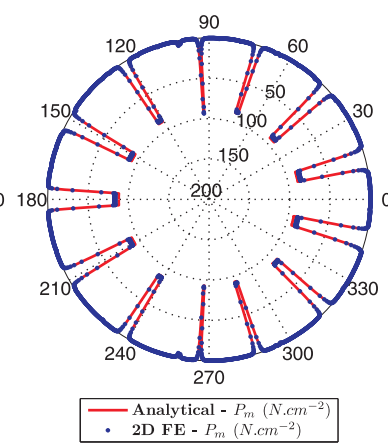

(c)

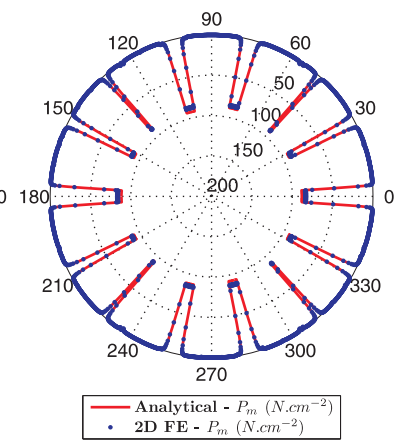

(d)

Fig. 17. Magnetic pressure $\left.P_{m}(\nu, \theta)\right|_{r=R_{e}}$ for a 24 stator slots structure (with $\beta_{s}=0.6, L_{d s}=L_{d r}$ and $n_{s} I_{e x c}=1200 A$.turn): (a) 10 rotor teeth, (b) 11 rotor teeth, (c) 13 rotor teeth and (d) 14 rotor teeth

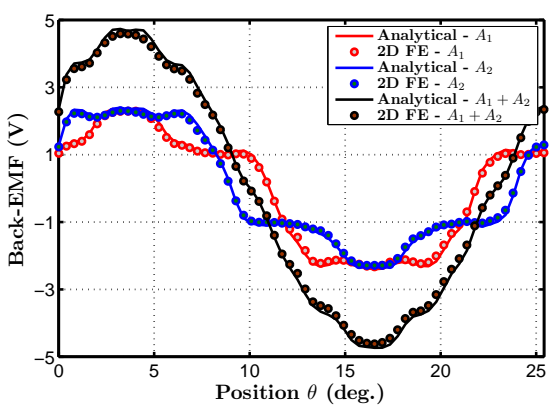

(a)

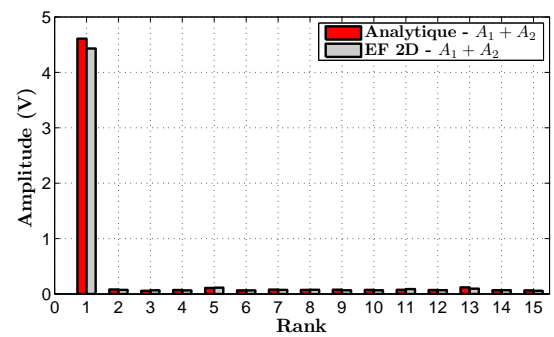

(b)

Fig. 16. Back-EMF waveform (a) and its spectra (b) for a 24-14 slots structure and double-layer winding configuration (with $\beta_{s}=0.6, L_{d s}=$ $L_{d r}, n_{s} I_{e x c}=1200$ A.turn and $\Omega=1300 \mathrm{rpm}$ )

magnetic field distribution. This phenomenon was extensively studied in the literature, in particular for PM synchronous machines [40][41], switched-reluctance machine [42] or induction machine [43][44], since it could lead to significant noise and vibration. Hence, some configurations, especially those with odd number of rotor slots, can also exhibit UMF. In [45], using Maxwell's stress tensor method, an overall Maxwell pressure distribution $P_{m}$ in the air-gap can be derived. After, some assumptions (neglecting tangential component of magnetic field $H_{t}$ and high permeability of iron), $P_{m}$ can be expressed as

$$
P_{m} \approx \frac{B_{r}^{2}}{2 \mu_{0}}
$$

with $B_{r}$ the radial flux density in the centre of the air-gap. After, the global force acting on the rotor (at a given position $\theta$ ) can be decomposed in Cartesian coordinates as

$$
\left\{\begin{array}{l}
F_{x}(\theta)=R_{e} L_{a} \int_{0}^{2 \pi}\left(\frac{-B_{r}^{2}}{2 \mu_{0}}\right) \cos (\nu) d \nu \\
F_{y}(\theta)=R_{e} L_{a} \int_{0}^{2 \pi}\left(\frac{-B_{r}^{2}}{2 \mu_{0}}\right) \sin (\nu) d \nu
\end{array}\right.
$$

\section{B. Comparison with Finite-Element analysis}

Parameters of Table I are still considered in this section for the both analytical model and FE simulations. Configurations with 24 stator slots are principally considered due to space limitations but the method could be applied to any statorrotor configuration. In Fig. 17, magnetic pressure $P_{m}$ along the air-gap is compared with the analytical model and with FE simulations and respectively for, 10,11, 13 and 14 rotor teeth (with 24 stator slots). Good agreement is observed with FE Analysis and, thanks to a representation in polar coordinates, we can see that configurations with 11 and 13 rotor teeth could exhibit UMF. Applying (27), it was shown that, indeed, even (10 and 14 teeth) rotor teeth configurations do not exhibit UMF, while odd one (11 and 13 teeth) does. In Fig. 18, analytically predicted and FE calculted UMF are compared, for 11 and 13 rotor teeth configurations. The analytical model predicts fairly UMF and, consequently, their influences on the level of noise or vibrations should be considered in designing machines.

\section{CONCLUSION}

In this work, an analytical model for Field-Excited FluxSwitching machine is developed taking into account the inherent double-saliency of this topology. The approach to model the air-gap flux density is based on MMF-permeance theory. A general expression for the magnetomotive force is derived as a Fourier series, as well as the doubly-slotted air-gap reluctance, assuming idealized flux paths under the slot opening.

Extensive comparisons with 2D FE results were performed and it is shown that the model can accurately predict the radial air-gap field distribution at no-load. Moreover, the model is suitable for multi-phase structures that have different rotor topologies.

Furthermore, analytical expressions have been presented to assess phase flux-linkage and back-EMF waveforms, depending on stator and rotor teeth configurations and/or phase 

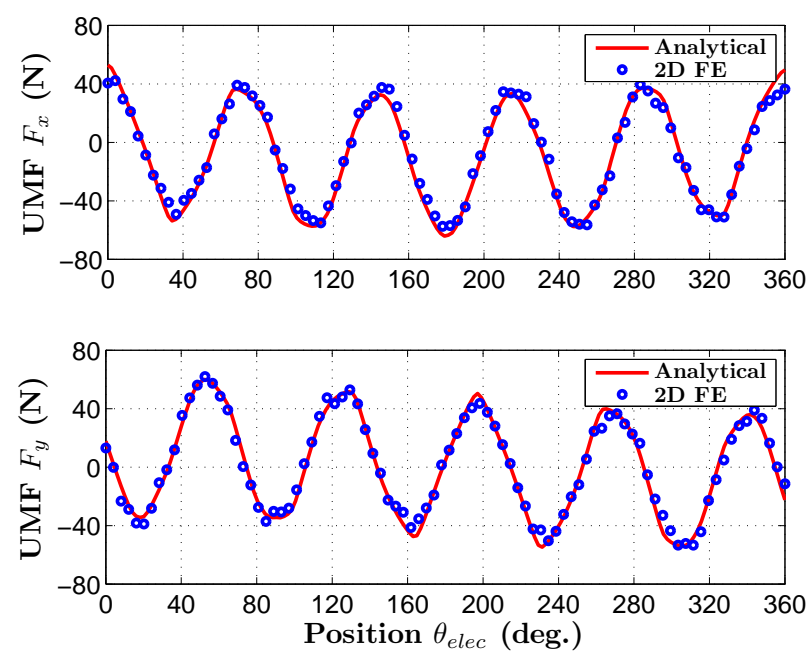

(a)
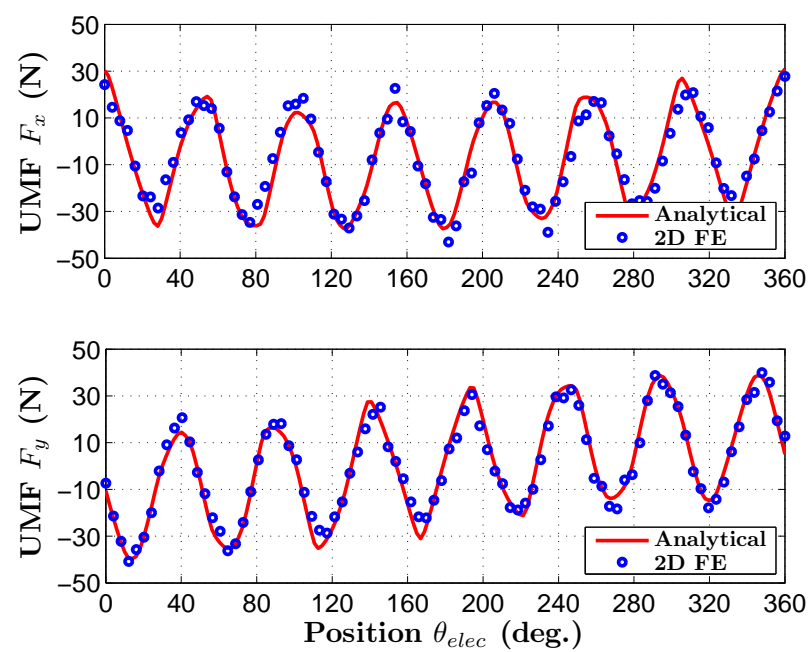

(b)

Fig. 18. Evolution of UMF ( $F_{x}$ and $F_{y}$ ) as function of rotor position $\theta_{\text {elec }}$ for a 24 stator slots structure (with $\beta_{s}=0.6, L_{d s}=L_{d r}$ and $n_{s} I_{e x c}=$ 1200A.turn): (a) 11 rotor teeth and (c) 13 rotor teeth

winding configurations. Close agreements with FE analysis have been demonstrated, showing a clear advantage of the analytical model with regard to computation time.

The last section of the paper focused on radial force calculation. Indeed, some rotor configurations could exhibit UMF. Once again, a good prediction of the magnetic force is achieved allowing the investigation of vibrations of magnetic origin. On-load performance, with the air-gap armature reaction field calculations, will be described in a subsequent part of this paper.

\section{APPENDIX A}

\section{AIR-GAP FIELD DISTRIBUTION FOR 3 PHASE CONFIGURATIONS}

Figs. 19, 20, 21 and 22 compare analytical predictions and FE simulations of the radial flux density $B_{r}$ in a 24 stator slots (3 phases) having 10,11,13 and 14 rotor teeth, respectively.

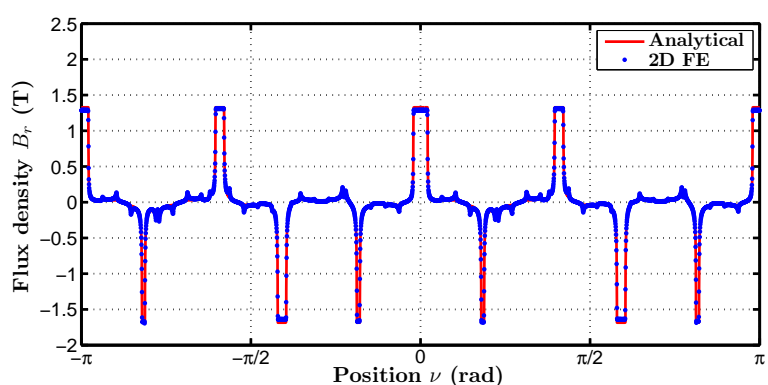

(a)

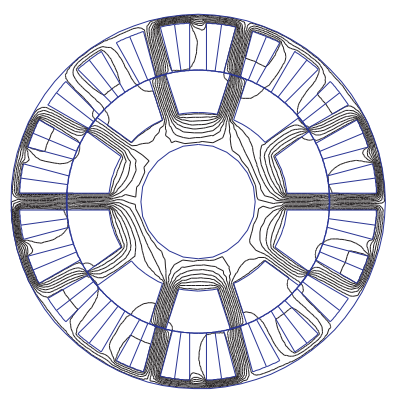

(b)

Fig. 19. Magnetic flux density in middle of air-gap $\left.B_{r}(\nu, \theta)\right|_{r=R_{e}}$ for a 24-10 slots configuration (3 phase) (with $\beta_{s}=0.6, L_{d s}=L_{d r}$ and $n_{s} I_{\text {exc }}=1200$ A.turn): (a) $B_{r}$ distribution for 24-10 slots configuration and (b) the magnetic flux lines with FE software

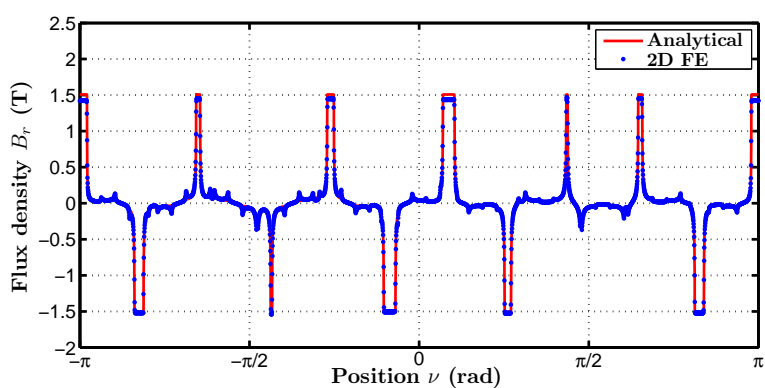

(a)

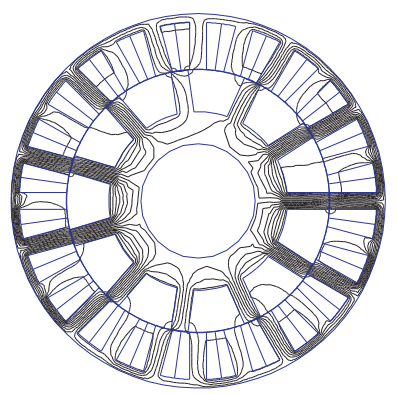

(b)

Fig. 20. Magnetic flux density in middle of air-gap $\left.B_{r}(\nu, \theta)\right|_{r=R_{e}}$ for a 24-11 slots configuration (3 phase) (with $\beta_{s}=0.6, L_{d s}=L_{d r}$ and $n_{s} I_{\text {exc }}=1200$ A.turn): (a) $B_{r}$ distribution for 24-11 slots configuration and (b) the magnetic flux lines with FE software

\section{ACKNOWLEDGMENT}

The authors would like to thank Leroy Somer (who are part of Emerson) and Agence Nationale de la Recherche (ANR) 


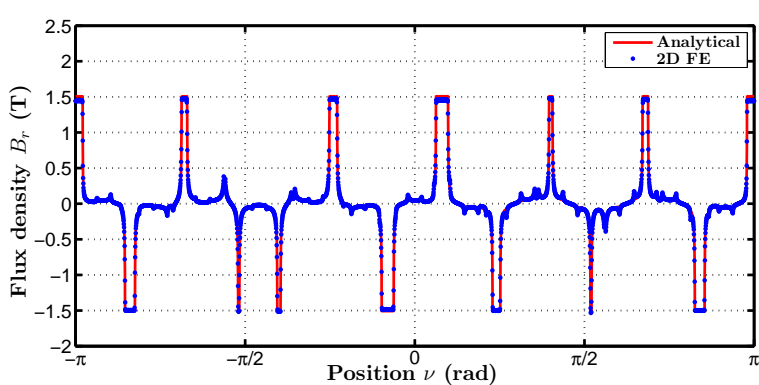

(a)

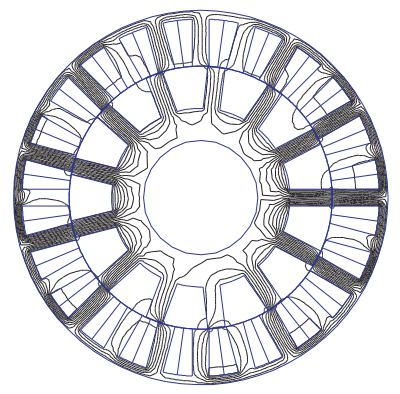

(b)

Fig. 21. Magnetic flux density in middle of air-gap $\left.B_{r}(\nu, \theta)\right|_{r=R_{e}}$ for a 24-13 slots configuration (3 phase) (with $\beta_{s}=0.6, L_{d s}=L_{d r}$ and $n_{s} I_{e x c}=1200$ A.turn): (a) $B_{r}$ distribution for 24-13 slots configuration and (b) the magnetic flux lines with FE software

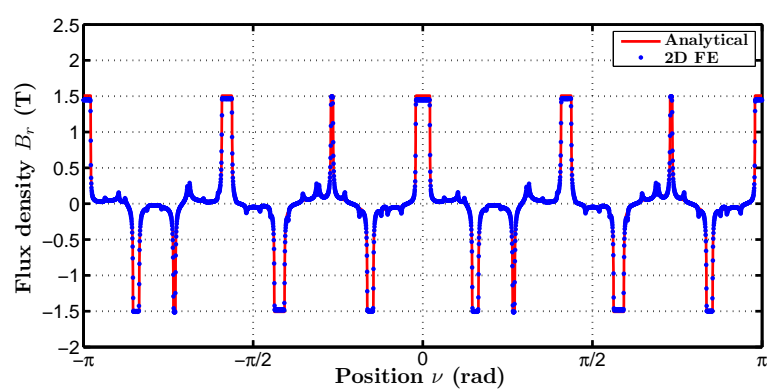

(a)

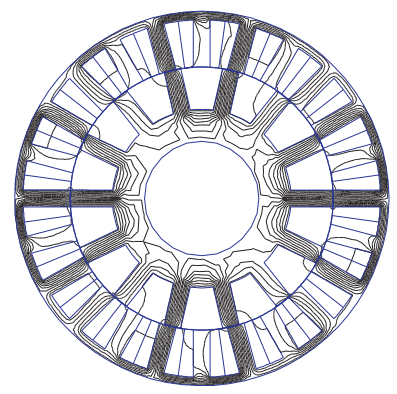

(b)

Fig. 22. Magnetic flux density in middle of air-gap $\left.B_{r}(\nu, \theta)\right|_{r=R_{e}}$ for a 24-14 slots configuration (3 phase) (with $\beta_{s}=0.6, L_{d s}=L_{d r}$ and $n_{s} I_{e x c}=1200$ A.turn): (a) $B_{r}$ distribution for 24-14 slots configuration and (b) the magnetic flux lines with FE software

for their support.

\section{REFERENCES}

[1] S. E. Rauch and L. J. Johnson, "Design principles of flux-switch alternators," Power Apparatus and Systems, Part III. Transactions of the American Institute of Electrical Engineers, vol. 74, no. 3, pp. 1261 -1268 , jan. 1955.

[2] B. Sarlioglu, Y. Zhao, and T. Lipo, "A novel doubly salient single phase permanent magnet generator," in Industry Applications Society Annual Meeting, 1994., Conference Record of the 1994 IEEE, oct 1994, pp. 9 -15 vol.1.

[3] E. Hoang, A. H. Ben-Ahmed, and J. Lucidarme, "Switching flux permanent magnet polyphased synchronous machines," in 7th European Conference on Power Electronics and Applications, vol. 3, 1997, pp. 903-908.

[4] Z. Zhu and J. Chen, "Advanced flux-switching permanent magnet brushless machines," IEEE Trans. Magn., vol. 46, no. 6, pp. 1447 1453, june 2010.

[5] Z. Zhu, A. Thomas, J. Chen, and G. Jewell, "Cogging torque in fluxswitching permanent magnet machines," IEEE Trans. Magn., vol. 45, no. 10 , pp. $4708-4711$, oct. 2009.

[6] Y. Cheng, C. Pollock, and H. Pollock, "A permanent magnet flux switching motor for low energy axial fans," in Industry Applications Conference, 2005. Fourtieth IAS Annual Meeting. Conference Record of the 2005, vol. 3, oct. 2005, pp. $2168-2175$ Vol. 3 .

[7] E. Sulaiman, T. Kosaka, Y. Tsujimori, and N. Matsui, "Design of 12slot 10-pole permanant magnet flux-switching machine with hybrid excitation for hybrid electric vehicle," 2010, pp. $1-5$.

[8] E. Hoang, M. Lecrivain, S. Hlioui, and M. Gabsi, "Hybrid excitation synchronous permanent magnets synchronous machines optimally designed for hybrid and full electrical vehicle," in Power Electronics and ECCE Asia (ICPE ECCE), 2011 IEEE 8th International Conference on, 30 2011-june 3 2011, pp. $153-160$.

[9] E. Hoang, M. Gabsi, M. Lecrivain, and B. Multon, "Influence of magnetic losses on maximum power limits of synchronous permanent magnet drives in flux-weakening mode," in Industry Applications Conference, 2000. Conference Record of the 2000 IEEE, vol. 1, 2000, pp. $299-303$ vol.1.

[10] Y. Amara, E. Hoang, M. Gabsi, M. Lecrivain, and S. Allano, "Design and comparison of different flux-switch synchronous machines for an aircraft oil breather application," European Transactions on Electrical Power, vol. 15, pp. 497-511, 2005.

[11] Y. Amara, L. Vido, M. Gabsi, E. Hoang, A. Hamid Ben Ahmed, and M. Lecrivain, "Hybrid excitation synchronous machines: Energyefficient solution for vehicles propulsion," IEEE Trans. Veh. Technol., vol. 58, no. 5, pp. $2137-2149$, jun 2009.

[12] R. Owen, Z. Zhu, and G. Jewell, "Hybrid-excited flux-switching permanent-magnet machines with iron flux bridges," IEEE Trans. Magn., vol. 46, no. 6, pp. $1726-1729$, june 2010.

[13] W. Hua, M. Cheng, and G. Zhang, "A novel hybrid excitation fluxswitching motor for hybrid vehicles," IEEE Trans. Magn., vol. 45, no. 10 , pp. $4728-4731$, oct. 2009.

[14] E. Hoang, M. Lecrivain, and M. Gabsi, "A new structure of a switching flux synchronous polyphased machine with hybrid excitation," in Power Electronics and Applications, 2007 European Conference on, sept. 2007, pp. $1-8$.

[15] J. Chen, Z. Zhu, S. Iwasaki, and R. Deodhar, "Low cost flux-switching brushless ac machines," in Vehicle Power and Propulsion Conference (VPPC), 2010 IEEE, sept. 2010, pp. 1 -6.

[16] C. Pollock and M. Wallace, "The flux switching motor, a dc motor without magnets or brushes," in Industry Applications Conference, 1999. Thirty-Fourth IAS Annual Meeting. Conference Record of the 1999 IEEE, vol. 3, 1999, pp. $1980-1987$ vol.3.

[17] H. Pollock, C. Pollock, R. Walter, and B. Gorti, "Low cost, high power density, flux switching machines and drives for power tools," in Industry Applications Conference, 2003. 38th IAS Annual Meeting. Conference Record of the, vol. 3, oct. 2003, pp. 1451 - 1457 vol.3.

[18] A. Zulu, B. Mecrow, and M. Armstrong, "A wound-field three-phase flux-switching synchronous motor with all excitation sources on the stator," IEEE Trans. Ind. Appl., vol. 46, no. 6, pp. 2363 -2371, nov.-dec. 2010.

[19] — , "Topologies for wound-field three-phase segmented-rotor fluxswitching machines," in Power Electronics, Machines and Drives (PEMD 2010), 5th IET International Conference on, april 2010, pp. $1-6$.

[20] J. Chen and Z. Zhu, "Influence of the rotor pole number on optimal parameters in flux-switching pm brushless ac machines by the lumped- 
parameter magnetic circuit model," IEEE Trans. Ind. Appl., vol. 46, no. 4, pp. $1381-1388$, july-aug. 2010.

[21] Y. Pang, Z. Zhu, D. Howe, S. Iwasaki, R. Deodhar, and A. Pride, "Eddy current loss in the frame of a flux-switching permanent magnet machine," IEEE Trans. Magn., vol. 42, no. 10, pp. 3413 -3415, oct. 2006.

[22] Z. Zhu, Y. Pang, D. Howe, S. Iwasaki, R. Deodhar, and A. Pride, "Analysis of electromagnetic performance of flux-switching permanentmagnet machines by nonlinear adaptive lumped parameter magnetic circuit model,” IEEE Trans. Magn., vol. 41, no. 11, pp. 4277 - 4287, nov. 2005

[23] B. Gysen, E. Ilhan, K. Meessen, J. Paulides, and E. Lomonova, "Modeling of flux switching permanent magnet machines with fourier analysis," IEEE Trans. Magn., vol. 46, no. 6, pp. 1499 -1502, june 2010.

[24] E. Ilhan, B. Gysen, J. Paulides, and E. Lomonova, "Analytical hybrid model for flux switching permanent magnet machines," IEEE Trans. Magn., vol. 46, no. 6, pp. $1762-1765$, june 2010

[25] W. J. Gibbs, Conformal transformations in electrical engineering. London: Chapman \& Hall, 1958.

[26] V. Hamata and B. Heller, Harmonic field effects in induction machines. Elsevier Scientific Pub. Co., 1977.

[27] Z. Zhu and D. Howe, "Instantaneous magnetic field distribution in brushless permanent magnet dc motors. iii. effect of stator slotting," IEEE Trans. Magn., vol. 29, no. 1, pp. 143 -151, jan 1993.

[28] D. Zarko, D. Ban, and T. Lipo, "Analytical calculation of magnetic field distribution in the slotted air gap of a surface permanent-magnet motor using complex relative air-gap permeance," IEEE Trans. Magn., vol. 42, no. 7 , pp. 1828 - 1837, july 2006 .

[29] —-, "Analytical solution for cogging torque in surface permanentmagnet motors using conformal mapping," IEEE Trans. Magn., vol. 44, no. 1 , pp. $52-65$, jan. 2008.

[30] T. Lubin, T. Hamiti, H. Razik, and A. Rezzoug, "Comparison between finite-element analysis and winding function theory for inductances and torque calculation of a synchronous reluctance machine," IEEE Trans. Magn., vol. 43, no. 8, pp. 3406 -3410, aug. 2007.

[31] U. Kim and D. Lieu, "Magnetic field calculation in permanent magnet motors with rotor eccentricity: with slotting effect considered," IEEE Trans. Magn., vol. 34, no. 4, pp. 2253 -2266, jul 1998.

[32] G. Dajaku and D. Gerling, "Stator slotting effect on the magnetic field distribution of salient pole synchronous permanent-magnet machines," IEEE Trans. Magn., vol. 46, no. 9, pp. 3676 -3683, sept. 2010.

[33] Z. Zhu, L. Wu, and Z. Xia, "An accurate subdomain model for magnetic field computation in slotted surface-mounted permanent-magnet machines," IEEE Trans. Magn., vol. 46, no. 4, pp. 1100 -1115, april 2010.

[34] T. Lubin, S. Mezani, and A. Rezzoug, "Exact analytical method for magnetic field computation in the air gap of cylindrical electrical machines considering slotting effects," IEEE Trans. Magn., vol. 46, no. 4 , pp. $1092-1099$, april 2010.

[35] Z. Liu and J. Li, "Analytical solution of air-gap field in permanentmagnet motors taking into account the effect of pole transition over slots," IEEE Trans. Magn., vol. 43, no. 10, pp. 3872 -3883, oct. 2007.

[36] F. Dubas and C. Espanet, "Analytical solution of the magnetic field in permanent-magnet motors taking into account slotting effect: Noload vector potential and flux density calculation," IEEE Trans. Magn., vol. 45, no. 5, pp. $2097-2109$, may 2009.

[37] R. Owen, Z. Zhu, A. Thomas, G. Jewell, and D. Howe, "Alternate poles wound flux-switching permanent-magnet brushless ac machines," IEEE Trans. Ind. Appl., vol. 46, no. 2, pp. 790 -797, march-april 2010.

[38] J. Chen and Z. Zhu, "Winding configurations and optimal stator and rotor pole combination of flux-switching pm brushless ac machines," IEEE Trans. Energy Convers., vol. 25, no. 2, pp. 293 -302, june 2010.

[39] H. Tiegna, A. Bellara, Y. Amara, and G. Barakat, "Analytical modeling of the open-circuit magnetic field in axial flux permanent magnet machines with semi-closed slots," IEEE Trans. Magn., vol. PP, no. 99, p. 1, 2011.

[40] Z. Zhu, Z. Xia, L. Wu, and G. Jewell, "Analytical modeling and finite-element computation of radial vibration force in fractional-slot permanent-magnet brushless machines," IEEE Trans. Ind. Appl., vol. 46, no. 5, pp. $1908-1918$, sept.-oct. 2010.

[41] Z. Liu and J. Li, "Accurate prediction of magnetic field and magnetic forces in permanent magnet motors using an analytical solution," IEEE Trans. Energy Convers., vol. 23, no. 3, pp. 717 -726, sept. 2008.

[42] M. Anwar and O. Husain, "Radial force calculation and acoustic noise prediction in switched reluctance machines," IEEE Trans. Ind. Appl., vol. 36, no. 6, pp. $1589-1597$, nov/dec 2000.
[43] S. Verma and A. Balan, "Determination of radial-forces in relation to noise and vibration problems of squirrel-cage induction motors," IEEE Trans. Energy Convers., vol. 9, no. 2, pp. 404 -412, jun 1994.

[44] D. Im, J. Chang, S. Park, B. Kwon, J. Hong, and B. Kim, "Analysis of radial force as a source of vibration in an induction motor with skewed slots," IEEE Trans. Magn., vol. 33, no. 2, pp. 1650 -1653, mar 1997.

[45] J. Le Besnerais, V. Lanfranchi, M. Hecquet, and P. Brochet, "Optimal slot numbers for magnetic noise reduction in variable-speed induction motors," IEEE Trans. Magn., vol. 45, no. 8, pp. 3131 -3136, aug. 2009.

Gaussens Benjamin was born in Toulouse, France, in 1987. He received the M.Sc. degree in electrical engineering from the Institut National Polytechnique (ENSEEIHT), Toulouse, France. He is currently working toward the Ph.D. degree still in electrical engineering at SATIE, ENS Cachan, CNRS, UniverSud. His current research interests include design of innovative topology of electromagnetic actuators and their modeling.

Hoang Emmanuel was born in Antibes, France, in 1966. He received the "agrégation" in electrical engineering in 1990 and the Ph.D. degree from the Ecole Normale Supérieure de Cachan in 1995. Since 1990, he has worked with the electrical machine team in the SATIE laboratory. His research interests include the modeling of the iron losses in SRMs and the design, modeling, optimization, and control of novel topologies of PM machines.

De la Barrière Olivier was born in Paris, France, in 1982. He received the M.Sc. degree in electronics from the Ecole Nationale Superieure de l'Electronique et de ses Applications (ENSEA), and the Ph.D. degree in electrical engineering from the Ecole Normale Suprieure de Cachan. He is now a Reseacher at SATIE, ENS Cachan, CNRS, UniverSud. His research topics include analytical modelling of electrical actuators, and also the study of new magnetic materials for electrical engineering applications.

Saint-Michel Jacques was born in 1949. He received the degree in engineering from Ecole Centrale de Paris, Paris, France, in 1972, and the Ph.D. degree from the University of Paris VI, Paris. From 1972 to 1982, he was with the French National Scientific Research Center (CNRS). In 1982, he joined Jeumont Schneider as the Head of the Design and Planning Department and remained with them until 1990. In 1990, he joined Leroy-Somer Motor, Angoulême, France, as a Technical Manager, becoming Scientific Director in 1998.

Lécrivain Michel was born in Barneville, France. He received the degree in electrical engineering from the Conservatoire National des Arts et Métiers (CNAM, Paris, France) in 1981. In 1997 he joined SATIE laboratory as a Research Engineer. His research interests include the design and control of new hybrid machines and novel permanent-magnet machines for automotive applications.

Gabsi Mohamed received the Ph.D. degree in electrical engineering from University of Paris-VI in 1987 and the HDR in 1999 from University of Paris-XI (Orsay, France). Since 1990, he has been working with the electrical machine team (SETE, Systèmes d'Energies pour le Transport et l'Environnement) of SATIE laboratory where he is currently a Full Professor and the Director of the Electrical Engineering Department. His research interests include SRM, vibrations and acoustic noise, and PM machines. 